\title{
EDUKASI POLA HIDUP SEHAT KEPADA MASYARAKAT DI KELURAHAN MANJAHLEGA KOTA BANDUNG DALAM MENANGGULANGI OBESITAS SEBAGAI FAKTOR RESIKO PENYAKIT KARDIOVASKULAR
}

\author{
Patonah $^{1}$, Lia Marliani' ${ }^{2}$, Yani Mulyani ${ }^{3)}$ \\ Sekolah Tinggi Farmasi Bandung ${ }^{1)}$ \\ Sekolah Tinggi Farmasi Bandung ${ }^{2)}$ \\ Sekolah Tinggi Farmasi Bandung ${ }^{3)}$
}

\begin{abstract}
ABSTRAK
Prevalensi penyakit tidak menular yang terus meningkat di Indonesia, mengakibatkan naiknya beban biaya kesehatan dan menurunkan produktivitas bangsa. Salah satu factor resiko utama penyakit tidak menular adalah obesitas. Obesitas merupakan kelebihan berat badan sebagai akibat dari penimbunan lemak yang berlebihan dalam tubuh. Akumulasi penimbunan lemak terjadi ketika asupan makanan lebih besar dari energi yang digunakan untuk aktifitas. Salah satu upaya pemerintah untuk mengatasi masalah penyakit tidak menular adalah program masyarakat hidup sehat (GERMAS). Kegiatan ini bertujuan untuk melakukan sosialisasi program GERMAS agar masyarakat memahami pentingnya pola hidup sehat. Kegiatan dilaksanakan di Kelurahan Manjahlega, RW 08 bekerjasama dengan ketua RT, RW dan ketua PKK. Edukasi dilakukan dengan 3 fokus utama termasuk edukasi meningkatkan aktivitas fisik, edukasi pola diet sehat, dan pemeriksaan kesehatan terdiri dari IMT (indeks massa tubuh), lingkar pinggang, tekanan darah, asam urat, kolesterol dan glukosa darah. Kegiatan dihadiri oleh laki-laki dan perempuan dengan usia rata-rata adalah 57 tahun. Beberapa peserta telah didiagnosa oleh dokter menderita hipertensi, hyperlipidemia, hiperurikemia, dan atau diabetes mellitus. Kesimpulan: kegiatan ini memberikan dampak positif terhadap perbaikan pemahaman dan pengetahuan masyarakat mengenai GERMAS.
\end{abstract}

Kata kunci: Obesitas, edukasi, Germas

\begin{abstract}
The prevalence of non-communicable diseases that continues to increase in Indonesia has resulted in an increase in the burden of health costs and reduced national productivity. One of the main risk factors for non-communicable diseases is obesity. Obesity is overweight as a result of accumulating excessive fat in the body. Accumulation of fat accumulation occurs when food intake is greater than the energy used for activity. One of the government's efforts to tackle the problem of non-communicable diseases is the community health program (GERMAS). This activity aims to disseminate the GERMAS program so that people understand the importance of a healthy lifestyle. The activity was carried out in the Manjahlega Village, RW 08 in collaboration with the RT, RW chairman and PKK chairman. Education is carried out with 3 main focuses including education to increase physical activity, education of healthy diet, and health checks consisting of BMI (body mass index), waist circumference, blood pressure, gout, cholesterol and blood glucose. The activity was attended by men and women with an average age of 57 years. Some participants have been diagnosed by doctors suffering from hypertension, hyperlipidemia, hyperuricemia, and / or diabetes mellitus. Conclusion: this activity has a positive impact on improving people's understanding and knowledge about GERMAS.
\end{abstract}

Kata kunci: obesity, education, Germas

\section{PENDAHULUAN}

Masalah kesehatan utama yang dihadapi oleh Indonesia saat ini yaitu masih tingginya penyakit infeksi namun juga mulai meningkatnya prevalensi penyakit tidak menular (PTM) dan penyakitpenyakit yang seharusnya sudah teratasi muncul kembali. 
Sebelumnya, penyakit menular seperti infeksi saluran napas dan diare merupakan penyakit terbanyak dalam pelayanan kesehatan. Namun, dengan berubahnya gaya hidup masyarakat menjadi salah satu penyebab terjadinya pergeseran pola penyakit (transisi epidemiologi). Pada tahun 2015, penyakit tidak menular (PTM) antara lain stroke, penyakit jantung koroner (PJK), kanker dan diabetes mellitus menempati peringkat tertinggi (www.depkes.go.id).

Di era JKN (Jaminan

Kesehatan Nasional), anggaran pemerintah banyak terserap untuk mengatasi penyakit PJK, Gagal Ginjal Kronik, Kanker, dan Stroke. Hal tersebut, berpotensi menjadi beban yang luar biasa terhadap keuangan negara. Jika kenaikan prevalensi PTM tidak segera dikelola dengan baik maka hal tersebut dapat menurunkan produktivitas sumber daya manusia, bahkan kualitas generasi bangsa. Hal ini berdampak pula terhadap besarnya beban dan biaya yang dikeluarkan pemerintah untuk menanggulangi PTM.

Menurut laporan Dinas Kesehatan kota Bandung, bahwa kecenderungan kesakitan dan kematian serta permintaan pelayanan kesehatan akan terus meningkat disebabkan kurangnya upaya yang signifikan. Oleh karena itu, perlu dilakukan dorongan upaya perubahan pola hidup sehat di masyarakat.

Salah satu faktor resiko utama penyakit tidak menular yang bisa dicegah adalah kelebihan bobot badan dan obesitas. Obesitas merupakan kelebihan berat badan sebagai akibat dari penimbunan lemak yang berlebihan dalam tubuh.
Akumulasi penimbunan lemak terjadi ketika asupan makanan lebih besar dari energi yang digunakan untuk aktifitas (Kelly, Yang, Chen, Reynolds, \& He, 2008).

Meningkatnya prevalensi obesitas merupakan masalah kesehatan utama diseluruh dunia. Kelebihan berat badan bukan hanya merupakan masalah estetik, namun merupakan faktor resiko untuk terjadinya penyakit kardiovaskuler, diabetes melitus tipe 2, hipertensi, bahkan kanker, yang pada akhirnya akan mengarah ke mortalitas (Park et al., 2010). Sekitar 2,8 juta orang dewasa meninggal setiap tahun terkait dengan kelebihan berat badan dan obesitas. Berdasarkan Riskesdas (2013), angka obesitas terus meningkat setiap tahunnya, pada laki-laki dewasa terjadi peningkatan dari 13,9\% pada tahun 2007 menjadi $19,7 \%$ pada tahun 2013. Sedangkan pada wanita dewasa terjadi kenaikan yang sangat ekstrim mencapai $18,1 \%$, dari $14,8 \%$ pada 2007 menjadi $32,9 \%$ pada tahun 2013(Dasar, 2013).

Faktor yang mempengaruhi bobot badan manusia antara lain tinggi badan, jenis kelamin, usia, lemak tubuh, densitas tulang serta masa otot. Beberapa metode yang digunakan untuk mengetahui lemak tubuh adalah indeks massa tubuh (IMT), lingkar pinggang, dan tebal lipatan kulit. Perhitungan yang paling sering digunakan adalah indeks massa tubuh (IMT), yang dikalkulasikan dengan cara membagi bobot badan $(\mathrm{kg})$ dengan tinggi badan (m) yang dikuadratkan. Walaupun hasil perhitungan ini tidak sempurna, namun IMT dianggap sebagai indikator bobot badan 
terhadap tinggi badan yang terbaik, serta berhubungan erat dengan proporsi lemak tubuh (Power \& Schulkin, 2013).

Etiologi obesitas melibatkan faktor genetik, aktivitas fisik, nutrisi dan gaya hidup yang mengakibatkan peningkatan asupan makanan dan berkurangnya pengeluaran energi sehingga mengakibatkan akumulasi kelebihan lemak tubuh. Seiring dengan berkembangnya pengetahuan, maka pola hidup manusia semakin berubah. Kesibukan manusia yang meningkat menyebabkan banyaknya makanan cepat saji (fast food), yang tinggi karbohidrat dan lemak. Jika terdapat kelebihan kalori dari asupan tinggi karbohidrat dan lemak, maka tubuh akan mengubah dan menyimpan nutrien energi ini sebagai trigliserida dalam jaringan adiposa. Seiring berjalannya waktu, jika kelebihan kalori ini dikonsumsi terus tanpa ada peningkatan pengeluaran energi, maka kelebihan lemak tubuh akan disimpan dan dapat berkembang menjadi overweight, bahkan obesitas (Power \& Schulkin, 2013).

Obesitas telah diketahui
sebagai factor resiko penyakit
kardiovaskular. Individu obesitas
atau kelebihan bobot badan
berkaitan dengan gangguan
metabolic (sindrom metabolik) yang
ditandai dengan kenaikan tekanan
darah, glukosa darah dan lipid darah
(Han \& Lean, 2016).

Sindrom metabolik sangat terkait dengan gaya hidup yang ditandai dengan akses mudah ke pasokan tanpa batas kalori tinggi, padat gizi rendah, makanan dan aktivitas fisik.
Orang gemuk yang secara metabolik sehat memiliki risiko lebih tinggi terkena penyakit jantung koroner, penyakit serebrovaskular, dan gagal jantung dibandingkan orang yang memiliki bobot badannya sehat secara metabolisme. Bahkan individu yang memiliki berat badan normal dapat memiliki kelainan metabolisme dan risiko serupa untuk kejadian penyakit kardiovaskular (Caleyachetty et al., 2017)

Salah satu upaya pemerintah untuk mengatasi masalah kesehatan adalah melalui kegiatan GERMAS (gerakan masyarakat hidup sehat). Saat ini, Germas fokus pada 3 kegiatan yaitu: Melakukan aktivitas fisik 30 menit per hari, 2) Mengonsumsi buah dan sayur; dan 3) Memeriksakan kesehatan secara rutin (www.depkes.go.id).

Upaya tersebut disambut oleh Pemerintah provinsi Jawa Barat, kota Bandung khususnya, dengan melakukan sosialisasi GERMAS (gerakan masyarakat hidup sehat) dengan harapan terwujudnya SDM masyarakat yang kreatif dan inovatif serta mampu menjadi penguatan peran kota sebagai smart city.

Kegiatan pengabdian kepada masyarakat ini bertujuan untuk memberikan edukasi pola hidup sehat dengan 3 hal yaitu 1) Melakukan aktivitas fisik 30 menit per hari, 2) Mengonsumsi buah dan sayur; dan 3) pemeriksaan BMI, lingkar perut, dan glukosa darah.

\section{METODE PELAKSANAAN}

Kegiatan pengabdian dilakukan pada bulan Oktober dan November 2018 melalui koordinasi dengan ketua RW 08 dan ketua PKK 
kelurahan Manjahlega. Kegiatan ini melibatkan masyarakat di RW 08 kelurahan Manjahlega, Bandung. Kegiatan terdiri dari penyuluhan, penyebaran kuesioner untuk menilai tingkat pengetahuan masyarakat tentang Germas serta pemeriksaan kesehatan yang meliputi lingkar perut, Indeks massa tubuh (IMT), tekanan darah, kadar glukosa darah, kolesterol, dan asam urat menggunakan alat strip test merk Autocheck ${ }^{\circledR}$.

Kegiatan edukasi melalui penyuluhan Germas dengan metode presentasi, ceramah dan diskusi. Presentasi menjelaskan tentang gerakan masyarakat hidup sehat melalu 3 fokus utama yaitu melakukan aktivitas fisik 30 menit per hari, mengonsumsi buah dan sayur; dan memeriksakan kesehatan secara rutin. Tingkat pengetahuan masyarakat mengenai pola hidup sehat dinilai menggunakan instrument kuesioner yang berisi 10 pertanyaan terdiri dari 7 pertanyaan tentang pengetahuan Germas dan 3 pertanyaan mengenai pelaksanaan pola hidup sehat yang sudah dijalankan oleh individu.

Pemeriksaan kesehatan dilakukan dengan mengukur BMI, lingkar perut, dan glukosa darah, kolesterol total, serta asam urat menggunakan alat strip test.

Data dihitung sebagai rata-rata dan standar deviasi ditampilkan dalam bentuk table dan grafik untuk pengambilan kesimpulan.

\section{HASIL DAN PEMBAHASAN}

Kegiatan Pengabdian Masyarakat dengan judul "Edukasi Pola Hidup Sehat Cegah Obesitas Sebagai Faktor Resiko Penyakit Tidak Menular" di kelurahan Manjahlega telah dilaksanakan pada tanggal 5 september dan 20 Oktober 2018 di kelurahan Manjahlega, Kecamatan Rancasari, Kota Bandung. Kegiatan diawali dengan penyebaran kuesioner untuk mengetahui tingkat pemahaman dan pengetahuan mengenai Germas. Hasil penyebaran kuesioner diolah dan ditampilkan dalam bentuk diagram (gambar 1 dan 2).

Berdasarkan hasil kuesioner diketahui sebagian besar masyarakat di kecamatan Manjahlega telah memiliki pengetahuan tentang gerakan masyarakat hidup sehat untuk mencegah penyakit tidak menular termasuk hipertensi (gambar 1). Hal tersebut bermanfaat untuk mengatasi dan mengendalikan komplikasi penyakit-penyakit tidak menular seperti hipertensi, diabetes, dan hiperlipidemia. Gaya hidup sehat dapat meningkatkan kepatuhan pengobatan dan kualitas hidup pasien. Hal ini sejalan dengan hasil penelitian yang melaporkan bahwa terdapat hubungan yang kuat antara gaya hidup sehat dengan kualitas hidup pasien hipertensi (Amila, Sinaga, \& Sembiring, 2018). Hal tersebut dilaporkan juga oleh peneliti lain bahwa kepatuhan pasien dengan terapinya meningkatkan kualitas hidup pasien (Mollaoglu, Solmaz, \& Mollaoglu, 2015). 


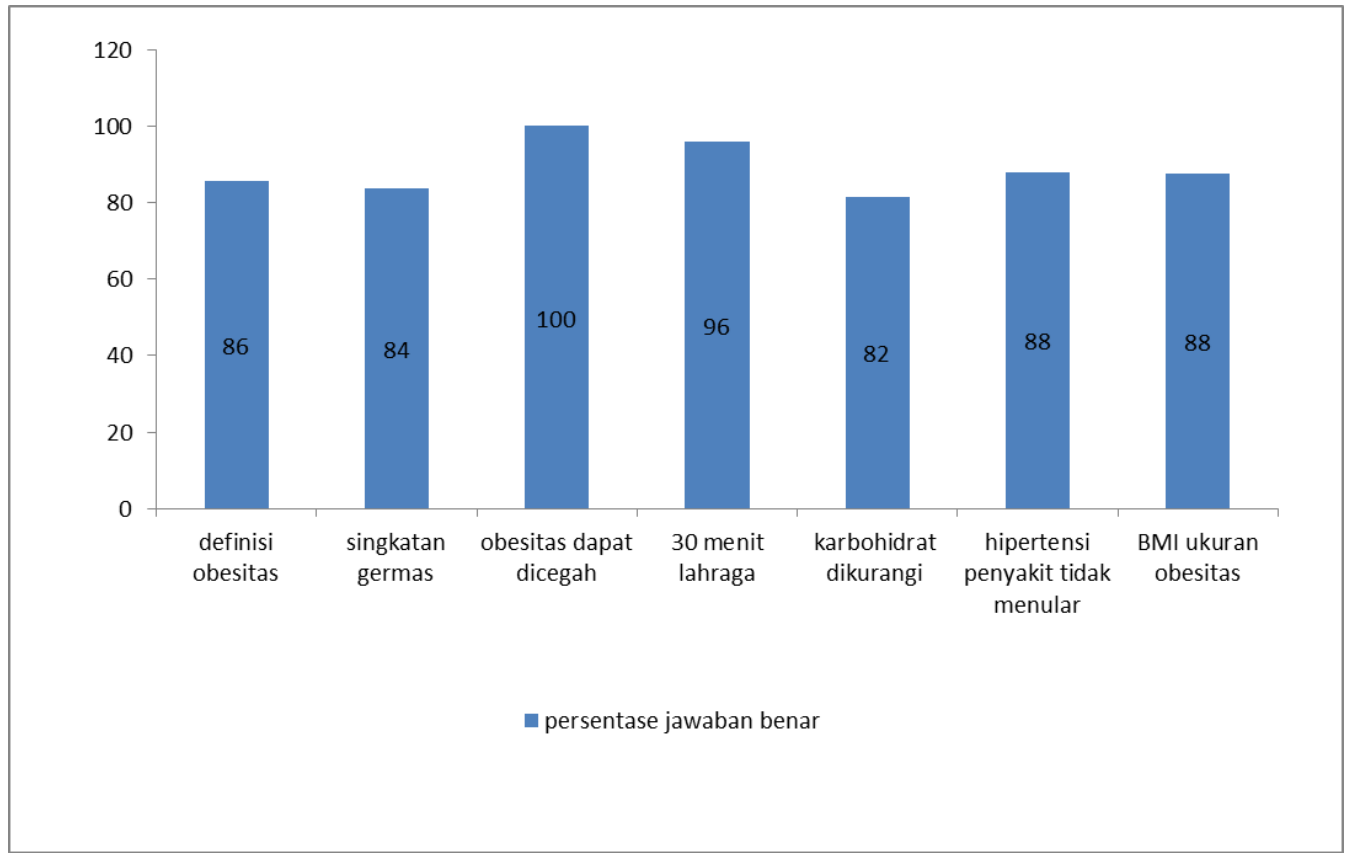

Gambar 1. Persentase Jawaban Benar Dalam Kuesioner Pengetahuan Germas

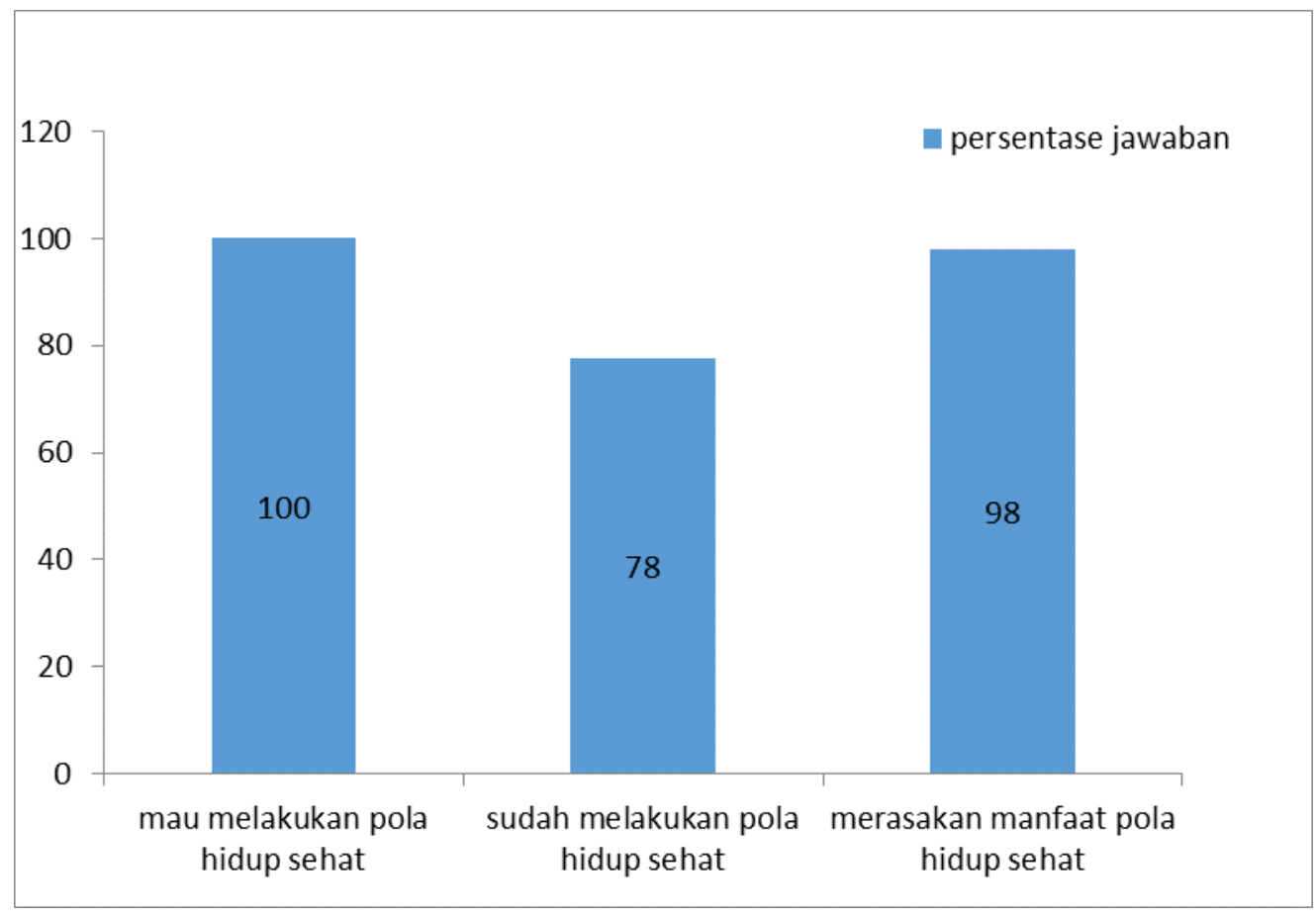

Gambar 2. Persentase Jawaban Mengenai Pelaksanaan Germas 
Tabel 1. Hasil Pemeriksaan Kesehatan Selama 2 Kali Pertemuan

\begin{tabular}{llll}
\hline No & Pemeriksaan & bulan ke 1 & bulan ke 2 \\
\hline 1 & Indeks Massa Tubuh & $25,5 \pm 3,7$ & $24,4 \pm 4,4$ \\
2 & Lingkar perut (cm) & $80,4 \pm 9,7$ & $86,8 \pm 10,3$ \\
3 & Tekanan darah sistolik (mmHg) & $124 \pm 15,7$ & $133,8 \pm 21,0$ \\
4 & Tekanan darah diastolik (mmHg) & $81,7 \pm 10,3$ & $79,9 \pm 13,9$ \\
5 & Glukosa darah (mg/dL) & $112,1 \pm 40,1$ & $154,7 \pm 66,6$ \\
6 & Asam urat (mg/dL) & $5,9 \pm 1,5$ & $5,6 \pm 1,3$ \\
7 & Kolesterol darah (mg/dL) & $296,7 \pm 25,0$ & $234,0 \pm 66,8$ \\
\hline
\end{tabular}

Sebagian besar masarakat memiliki telah melakukan pola hidup sehat dan merasakan manfaatnya (gambar 2). Pola hidup sehat sangat penting untuk terus menerus disosialisasikan agar menjadi kebiasaan yang rutin dilakukan dan menjadi kebutuhan untuk senantiasa menerapkan pola hidup sehat. Mengingat hasil pemeriksaan kesehatan yang dilakukan dalam 2 kali pengukuran terdapat kecenderungan kenaikan lingkar perut, tekanan darah, glukosa, asam urat dan kolesterol darah. Kenaikan angka lingkar perut menggambarkan kecenderungan obesitas. Hal tersebut perlu diwaspadai karena obesitas merupakan salah satu factor resiko dominan untuk penyakit kardiovaskular. Upaya pengaturan makanan sehat dengan komposisi gizi seimbang sesuai kebutuhan indvidu untuk mengendalikan indeks massa tubuh (IMT) (Mandviwala, Khalid, \& Deswal, 2016).

Kenaikan tekanan darah yang tidak terdeteksi dini dan tidak dikelola dengan baik berpotensi menurunkan kualitas hidup penderitanya akibat komplikasi kardiovaskular. Hingga saat ini hipertensi masih dianggap sebagai silent killer di dunia dan di negaranegara berkembang termasuk Indonesia. Untuk mengatasi hal tersebut perlu strategi di tingkat komunitas masyarakat melalui Germas (Bremner, 2002).

Kegiatan dihadiri masyarakat dengan menyimak paparan materi edukasi, dilanjutkan dengan pengisian kuesioner oleh peserta masayarakat mengeai pemahaman dan pengetahuan tentang Germas. Selanjutnya dilakukan pengukuran lingkar perut, bobot badan, tinggi badan, tekanan darah, kadar glukosa, kadar kolesterol, kadar asam urat (Tabel 1). Hasil pemeriksaan digunakan sebagai bahan diskusi dan konseling tiap individu dengan apoteker. Hasil pemeriksaan masih banyak peserta yang belum terkontrol penyakitnya walaupun sudah mendapat obat. Beberapa hal yang menjadi penyebabnya adalah ketidakpatuhan dalam pengobatan, belum memahami target terapinya, belum konsisten memperbaiki pola makan dan aktifitas fisiknya.

Pada saat paparan materi edukasi sebagian besar peserta sangat antusias dengan menyampaikan berbagai pertanyaan terkait pengelolaan penyakit hipertensi, diabetes, hiperlipidemia, hiperurikemia dalam hal terapi non farmakologi dan terapi farmakologi 
yang telah mereka dapatkan sebelumnya. Secara umum, masih banyak yang belum memahami dan melaksanakan pola hidup sehat untuk menurunkan resiko penyakit tidak menular.

Berdasarkan hasil pemeriksaan kadar kolesterol, secara umum masyarakat memiliki kadar kolesterol di atas normal atau hiperlipidemia (table 1). Hal tersebut memerlukan perhatian yang serius karena hiperlipidemia merupakan factor resiko utama terjadinya penyakit jantung koroner (Mandviwala et al., 2016) termasuk hipertensi, diabetes mellitus, hiperlipidemia, dan inflamasi kronik (Lavie et al., 2016).

Hasil edukasi melalui metode presentasi dan konsultasi sangat membantu peserta untuk memahami lebih dalam dan lebih luas mengenai Germas dan pengelolaan penyakit.

\section{KESIMPULAN}

Kegiatan

Pengabdian

Masyarakat dengan judul "Edukasi Pola Hidup Sehat Cegah Obesitas Sebagai Faktor Resiko Penyakit Tidak Menular" kepada masyarakat Kelurahan Manjahlega RW 08 bekerjasama dengan ketua RT, RW dan ketua PKK setempat telah berhasil dilaksanakan dengan mendapat sambutan antusias masyarakat dan berharap terjalin kerjasama lebih lanjut antara PKK Manjahlega dan STFB dalam melaksanakan kegiatan edukasi kesehatan secara rutin.

Hasil kegiatan dapat disimpulkan bahwa secara umum pemahaman dan prilaku hidup sehat sudah cukup baik namun masih belum konsisten. Terdapat kecenderungan kenaikan tekanan darah, glukosa, asam urat namun masih dalam batas normal (perlu diwaspadai). Upaya edukasi pola hidup sehat perlu terus ditingkatkan untuk mendeteksi dini risiko penyakit tidak menular. Oleh Karena itu, pentingnya peran apoteker di masyarakat dalam melakukan sosialisasi Gerakan Masyarakat Hidup Sehat (Germas).

\section{UCAPAN TERIMAKASIH}

Peneliti mengucapkan terimakasih kepada P3M Sekolah Tinggi Farmasi Bandung yang telah mendanai kegiatan ini.

\section{REFERENSI}

Amila, A., Sinaga, J., \& Sembiring, E. (2018). Self Efficacy dan Gaya Hidup Pasien Hipertensi. Jurnal Kesehatan, 9(3), 360365.

Bremner, A. D. (2002). Antihypertensive medication and quality of life-silent treatment of a silent killer? Cardiovascular Drugs and Therapy, 16(4), 353-364.

Caleyachetty, R., Thomas, G. N., Toulis, K. A., Mohammed, N., Gokhale, K. M., Balachandran, K., \& Nirantharakumar, K. (2017). Metabolically healthy obese and incident cardiovascular disease events among 3.5 million men and women. Journal of the American College of Cardiology, 70(12), 1429-1437.

Kementerian Kesehatan Republik Indonesia. (2013). Riset Kesehatan Darasar tahun 2013. Jakarta.

Han, T. S., \& Lean, M. E. J. (2016). A clinical perspective of 
obesity, metabolic syndrome

and cardiovascular disease.

JRSM Cardiovascular Disease, 5, 2048004016633371.

Kelly, T., Yang, W., Chen, C.-S., Reynolds, K., \& He, J. (2008). Global burden of obesity in 2005 and projections to 2030. International Journal of Obesity, 32(9), 1431.

Lavie, C. J., De Schutter, A., Parto, P., Jahangir, E., Kokkinos, P., Ortega, F. B., ... Milani, R. V. (2016). Obesity and prevalence of cardiovascular diseases and prognosis - the obesity paradox updated. Progress in Cardiovascular Diseases, 58(5), 537-547.

Mandviwala, T., Khalid, U., \& Deswal, A. (2016). Obesity and cardiovascular disease: a risk factor or a risk marker? Current Atherosclerosis Reports, 18(5), 21.

Mollaoglu, M., Solmaz, G., \& Mollaoglu, M. (2015). Adherence to therapy and quality of life in hypertensive patients. Acta Clinica Croatica, 54(4.), 438-443.

Power, M. L., \& Schulkin, J. (2013). The evolution of obesity. JHU Press. 